Review

\title{
Consumer's Circular Behaviors in Relation to the Purchase, Extension of Life, and End of Life Management of Electrical and Electronic Products: A Review
}

\author{
Filippo Corsini *, Natalia Marzia Gusmerotti and Marco Frey \\ Istituto di Management (Institute of Management), Scuola Superiore Sant'Anna (Sant'Anna School of Advanced \\ Studies), 56127 Pisa, Italy; nataliamarzia.gusmerotti@santannapisa.it (N.M.G.); \\ marco.frey@santannapisa.it (M.F.) \\ * Correspondence: filippo.corsini@santannapisa.it
}

Received: 30 November 2020; Accepted: 10 December 2020; Published: 14 December 2020

\begin{abstract}
Nowadays, management of electrical and electronic equipment (EEE) and the related waste electrical and electronic equipment (WEEE) is a growing concern around the world and clearly an open issue to tackle in order to move towards a more circular economy. The goal of this review paper is to analyze and summarize research conducted exploring behaviors connected with purchases, extension of useful life, and management of end of life of electrical and electronic equipment. The results highlight several research exploring the determinants of WEEE recycling behavior, also in relation with different practices (e.g., online recycling); on the other hand other typologies of behaviors are less analyzed in the literature (e.g., purchase of used EEE products, donation of EEE products, participation in WEEE takeback activities established by firm operating in this sector, etc.). Moreover, the results suggest that the theoretical model adopted in many studies reveals its usefulness to predict the determinist of such circular consumer's behavior in relation to the purchase, extension of life, and end of life management of electrical and electronic products; however, in many cases, additional variables are needed to fully explain the behavior.
\end{abstract}

Keywords: circular economy; electrical and electronic products; e-waste; WEEE; consumer behavior; extension of life; end of life management; extended producer responsibility

\section{Introduction}

Nowadays, the traditional "take-make-dispose" model is currently questioned by the new paradigm of circular economy. During the last years, indeed, the urgent need to embrace new approaches able to minimize waste production and at the same time optimize resources and material consumption in order to maintain their value for as long as possible has been stressed [1]. More sustainable methods of consuming and managing materials and resources are becoming increasingly important on a global scale [2]. In such a context, the management of electrical and electronic equipment (EEE) and the related waste electrical and electronic equipment (WEEE) is a growing concern around the world and clearly an open issue to tackle in order to move towards a more circular economy.

In the last 20 years, with technological advances, industries have moved towards greater automation, which has increased the use of electrical and electronic equipment. At the same time, electrical and electronic products have become commonplace in the daily life of an average consumer. The development of advanced, faster, and more reliable processing and processing technologies has led to a reduction in the product life cycle, prompting consumers to purchase increasingly current products in terms of technology and performance, sending obsolete products for disposal. All these developments have in 
turn led to an exponential increase in the generation of electronic waste. According to Balde et al. [3], the per capita average of electronic waste generated by people around the world in 2014 was approximately $5.9 \mathrm{~kg}$ per capita.

In Europe, waste electrical and electronic equipment (WEEE) is currently considered one of the fastest growing waste streams, with an increase of approximately $3-5 \%$ per annum. This growth rate is approximately three times faster than other waste streams [4]. In 2016, from the latest data available through Eurostat, the input for consumption of electrical and electronic equipment was equal to $18.4 \mathrm{~kg}$ per capita while the production of WEEE was equal to approximately $8.7 \mathrm{~kg}$ per capita. It is clear that, in a constantly growing system of placement on the market and generation of waste, the role of the consumer in relation to the dynamics of purchase, extension of life, and recycling of electrical and electronic products is of utmost importance.

The relevance of such an issue has been also remarked by the recent "Circular Economy Action Plan" presented by the European Commission during the first months of 2020. More in detail, the commission will soon present a "Circular Electronics Initiative" to tackle such a problem that will include, among others, actions concerning: (I) implementation of the "right to repair", including a right to update obsolete software to foster reparation of electric and electronic equipment from consumers, and (II) implementation of an EU-wide take back scheme to foster consumers to return or sell back old mobile phones and tablets [5].

As presented above, consumer behaviors in fact might influence the volume of new products released for consumption (i.e., behaviors to avoid the purchase of unnecessary products and behaviors that lead to the extension of the useful life of the products in use, avoiding the purchase of new ones), acting as well as a stimulus for companies to incorporate eco-design principles (e.g., behaviors that prefer products with recycled, durable/easily repairable materials). Consumer behavior also determines the management dynamics of the end of life of electrical and electronic products. For example, these can create uncertainty regarding the volumes of waste available both in collective collection systems in the context of the dynamics of extended producer responsibility [6] and in the case of companies that intend to create closed supply chains by activating take-back processes. In fact, consumers who use appliances longer lead to a reduction in WEEE generated. The same applies to all those waste reduction behaviors such as sale and/or donation of used products. Table 1 presents some examples of sustainable behavior in relation to the purchase, use, and end-of-life management of electrical and electronic products.

Table 1. Some examples of sustainable behaviors in relation to electrical and electronic products.

\begin{tabular}{cccc}
\hline Purchase Behavior & Life Extension Behavior & Recycling Behavior & Tack-Back Participation Behavior \\
\hline $\begin{array}{c}\text { Avoid purchasing } \\
\text { unnecessary products }\end{array}$ & $\begin{array}{c}\text { Sale and/or donation of } \\
\text { electrical and electronic } \\
\text { equipment still functioning }\end{array}$ & $\begin{array}{c}\text { Recycling of electrical } \\
\text { and electronic products }\end{array}$ & $\begin{array}{c}\text { Participation in the return of end-of-life } \\
\text { products through take-back initiatives } \\
\text { offered by companies }\end{array}$ \\
\hline $\begin{array}{c}\text { Selection of products: e.g., made } \\
\text { from recyclable materials, more } \\
\text { durable/easily repairable products, } \\
\text { energy-efficient products, and } \\
\text { certified products like Ecolabel }\end{array}$ & $\begin{array}{c}\text { Extension of product } \\
\text { lifetime through reuse and } \\
\text { repair activities }\end{array}$ & \\
\hline $\begin{array}{c}\text { Purchase of used and/or } \\
\text { refurbished products }\end{array}$ & & \\
\hline
\end{tabular}

The goal of this review paper is to analyze and summarize research conducted exploring the four types of behaviors (Table 1): purchases, extension of useful life, and management of end of life of electrical and electronic equipment. Many researchers explored those behavior in relation to EEE or WEEE, trying to show the relationships between environmentally sensitive behaviors and other variables achieving different results [7-11]. Such research empirically shows relationships which involve not only sociopsychological variables but also sociodemographic variables, situational factors, costs, and the commitment required for a given behavior. Sometimes, the results of those research show a consistent trend in the relationship between a given variable and a behavior, and the aim of this paper is to underline those aspects. 
This paper is structured as follows. Firstly, we present a short section providing an overview of variables that can influence sustainable behaviors and the main theoretical frameworks adopted in research exploring the determinants of consumer behaviors. We then present the methodological process adopted in selecting the papers to be analyzed; the following section introduces and comments on some of the most relevant work related to purchases, extension of useful life, and management of end of life of electrical and electronic equipment. Finally, the last section provides conclusions, limitations of the research, and future research avenues.

\section{Theoretical Background: Variables That Can Influence Sustainable Behaviors}

Various studies have analyzed what may be the determinants of sustainable behavior in general. A wide range of studies use psychological factors to understand how a behavior originates.

Among the psychological factors, attitude to behavior is an important key factor. Thurstone [12] (p. 531), one of the first to define it, described behavioral attitude as "the sum total of a man's inclinations and feelings, prejudices, preconceived notions, ideas, fears, threats and beliefs on any specific subject". Thurstone [12] immediately underlined that attitudes are multifaceted; such an aspect was then supported by other researchers noticing a variety of relevant attitudinal properties. Katz and Stotland [13], for instance, described attitudes composed of three types of evaluative responses: cognitive, affective, and behavioral. According to the authors, cognitive response is based on the knowledge or information, the affective response is based on the feelings, while the behavioral response reflects how attitude affects the way a subject acts or behaves. Other scholars distinguished among the underlying functions of attitudes [14]. Thus, social scientists have long recognized the importance of attitude in determining a behavior.

Norms are also considered one of the important factors in determining people's behaviors among psychological variables. The basic categorization of norms distinguishes social norms and personal norms [15]. Although the definition of social norms is not uniform, they can be considered the behavioral standards shared by a group or a society. The subjective norm is the subjective perception of social norms and is defined as the perception of expectation by others. Finally, when a social norm is internalized, a personal norm is formed. Personal norms can be internalized moral rules, considered the perception of the correctness or incorrectness of a certain behavior [15].

Perceived behavioral control is another psychological factor often analyzed when determining sustainable behaviors generally understood; it represents the perception that a subject has of being able to carry out the desired behavior. The perceived behavioral control is, with respect to real control, a proxy that is an indirect measure of this and concerns exclusively what is the subjective perception but not the individual's effective control over behavior. Previous research underlined that a higher level of perceived control should increase the positive attitude towards pro-environmental behavior [16].

Finally, among the most important psychological variables, there is also behavioral intention, which represents the ability of a person to perform a certain behavior.

In many research, psychological variables are related to each other to explain the origin of a behavior. One of the most famous theories, for example, is that of planned behavior-Theory of planned behavior (TPB) — by Ajzen [17], which establishes a theoretical link between the concept of beliefs and evaluation criteria to explain behavior. This theory is often used as a theoretical foundation to explain some sustainable behaviors. The model formalizes the assumption that the anticipated satisfaction of an environmentally sustainable behavior and, consequently, its implementation are based on beliefs relating to the perceived benefits of this. Following this logic, environmentally sustainable behaviors are based on beliefs; personal, altruistic, and/or perceived environmental benefits; and the positive consequences associated with these types of behavior.

Specifically, the TPB is summarized in Figure 1, where it is clear how a behavior is influenced by the intention, which in turn is influenced by the attitudes to a certain type of behavior, by subjective norms, and by the perception of behavior control. 


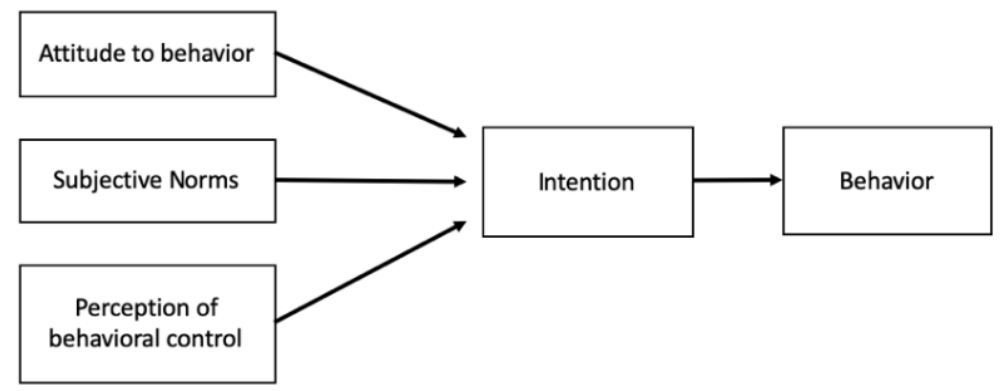

Figure 1. Theory of planned behavior.

In many studies, sociodemographic aspects are also considered variables that can directly influence consumer behaviors and have indirect effects on these behaviors through influences on psychological factors. The sociodemographic aspects generally analyzed include gender, age, educational qualification, and annual income. Kurisu [18] examined several researches on the relationships between sustainable behaviors and sociodemographic aspects. However, there is no consistent trend between these. First, the influence of sociodemographic aspects varies according to time, social situation, and reference behavior and secondly, it has also been pointed out by many studies that the ability to explain environmentally sustainable behavior through sociodemographic variables is quite limited $[19,20]$.

In some studies, factors related to costs are also considered [18], which can represent both an inhibiting factor for certain behaviors and a driving force. Consider, for example, the purchasing behavior of sustainable products that may have a higher price than other similar products or, on the contrary, the purchasing behavior of an energy efficient product capable of reducing costs during the use of a product. In addition to the monetary cost, other costs also fall into this category of variables, such as the time and effort required to maintain a certain behavior [21]. An example in the field under investigation might be related to the time needed to separate and dispose of an electrical and electronic product at the end of its life in the appropriate recycling facilities or to return it to a retailer who collects it.

There is another type of variable generally analyzed among the determinants behind sustainable behavior. Knowledge is a necessary but not always fundamental condition in behavior [22]. In fact, if a subject does not possess sufficient knowledge of a certain behavior and its impacts, they will not be able to implement it; however, even if a subject possesses sufficient knowledge of a behavior, it is not certain that they always adopt it. For instance, Oskamp et al. [23] found that a general knowledge of conservation was a significant variable in influencing environmentally responsible behavior in north American citizens.

Another type of variable related to environmentally sustainable behavior is the personality of the individual. For example, Rotter [24] proposes the "locus of control" as a measure of personality that expresses how much an individual believes that results depend on their own actions. The "locus of control" is a double concept, consisting of an "external control" and an "internal control". The belief that events can be controlled by external parties is a belief of external control. On the contrary, the belief that events can be guided by the behavior of the individual is a belief in internal control.

Finally, in addition to the factors previously presented, there are also situational factors such as the presence of facilities to carry out separate collection or the availability of certain products on the market [25]. For example, in the case of the purchase of a product, availability is an important situational factor. No matter how willing a user is to buy a modular smartphone, this is unlikely to happen if such a product is not available in the target market and therefore must be bought on another market. Situational factors also include those linked to incentives provided by institutions and/or companies for particular behaviors [26]. For instance, companies that have initiated trade-in mechanisms for end-of-life products can substantially affect the behavior of end-of-life management users of their products. 


\section{Methodology}

To provide some practical examples of behaviors, some evidences gathered from previous research on the subject are presented in the following sections of the paper. The research was based on the scientific literature identified by keywords. More in detail, the investigation was conducted from selection of relevant publications through keywords such as "EEE", "Electrical and Electronic Equipment", "WEEE", or "Waste Electrical and Electronic Equipment" together with key words like "behaviour" or "behavior" and keywords like "purchase" or "repair", or "recycling", etc. Boolean operators were used to specify the research that was conducted through the Scopus search engine. Then, we decided to retain just papers accepted in peer review journals and to reject contributions such as working paper, conference papers, and book chapters. By doing so, as suggested by Light and Pillemer [27], we improved consistently the quality of our analysis.

In order to refine the dataset and to filter from potential articles that were too generic, a systematic review of titles and abstracts was conducted. After this final filtering procedure, 36 papers were identified for dealing with the purchase, extension of life, and end of life management of electrical and electronic products. Those papers are presented in Table 2.

Table 2. Papers dealing with the purchase, extension of life, and end of life management of electrical and electronic products.

\begin{tabular}{cccc}
\hline Sustainable Purchase Behavior & Life Extension Behavior & Recycling Behavior & Tack-Back Participation Behavior \\
\hline & & Darby \& Obara [36]; Wang et al. [37]; Li et & \\
& al. [38]; Chi et al. [39]; Pérez-Belis et al. [40]; & \\
& Gutiérrez et al. [31]; & Ylä-Mella et al. [9]; Nowakowski [10]; & Manomaivibool \& Vassanadumrongdee \\
Saphores et al. [28]; Young et al. [7]; & Lilley et al. [32]; Hennies & Bovea et al. [41]; Nowakowski [42]; & [53]; Sabbaghi et al. [54]; Botelho et al. \\
Hassan \& Nor [8]; Pérez-Belis et al. & \& Stamminger [33]; & Shevchenko et al. [43]; Wang et al. [44]; & [55]; Budijati et al. [56]; Kianpour et al. \\
[29]; Danish et al. [30]. & Pérez-Belis et al. [34]; & Kumar [45], Borthakur \& Govind [46]; Park & [57]; Kumar [58]. \\
& Bovea et al. [35]. & et al. [47]; Kurisu et al. [48]; Mansuy et al. & \\
& & [49]; Hamdan \& Saidan [50]; Ardi et al. [36]; & \\
& & Huang et al. [51]; Delcea et al. [52]. \\
\hline
\end{tabular}

The identified and collected studies were then analyzed with the aim of searching for relationships and performing cross-case analyzes. After a review of the papers identified, a selection of those based on the impact in the academic field (citations based) has been presented in the following paragraphs. In particular, to draw a picture of the four behaviors mentioned above, the following paragraphs focus first on generic models that explain the purchasing behavior, extension of useful life, and management of end of life in several categories of consumer goods and then present models relating to electrical and electronic products.

\section{Results}

\subsection{Determinants and Models for Sustainable Purchasing Behavior in the Electrical and Electronic Products Sector}

Ecologically sustainable or "green" purchasing decisions in the daily behavior of consumers offer the possibility of reducing the environmental impact by replacing high-impact products. On the general theme of sustainable purchases, there is a great deal of research conducted in recent years. Joshi and Rahman [59] examine 53 empirical research published from 2000 to 2014, identifying various prevailing reasons, facilitators, or obstacles which influence the purchasing decision-making process towards green products. As the results show, environmental concerns, product characteristics, environmental knowledge, and subjective norms emerge as the main drivers, while high price, low availability, and lack of consumer confidence in green products emerge as the main barriers to purchase.

One of the most important research, conducted by Moser [60], uses the theory of planned behavior (TPB) as a theoretical framework for identifying the main antecedents of the behavior of purchasing sustainable products. In order to draw an overall picture of sustainable consumption, the author examines the purchasing behavior of several categories of consumer goods. The study takes into consideration the essential components of the TPB. However, in contrast to common interpretations 
of constructs, norms are not conceptualized as social norms but as personal norms, while perceived behavioral control is not interpreted generally but explicitly as willingness to pay-Willingness to Pay (WTP)—for sustainable products. Moser [60] concludes that WTP is the strongest predictor of green shopping behavior, followed by personal norms. The impact of the attitude to behavior from the study he conducted is instead not significant (Figure 2). According to these results, consumers need to be aware that their consumption behavior can make a difference. They also need to evaluate the benefits of green products and to understand why they are priced higher.

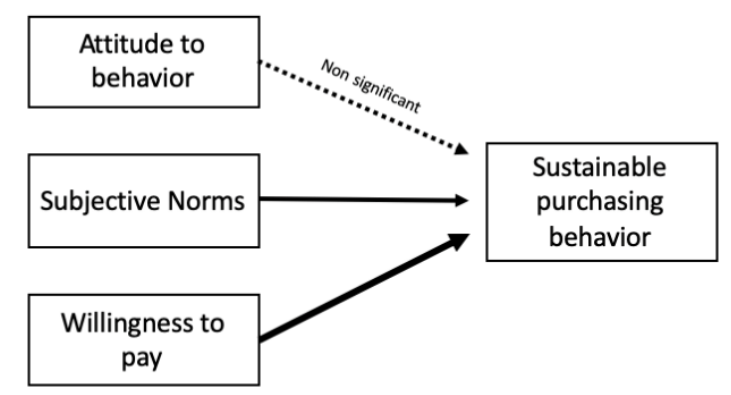

Arrows increase in size based on their predictive power.

Figure 2. Model tested and results in Moser's work [60].

As presented in Table 2, there are also more specific research that analyze purchasing dynamics of electrical and electronic products. The one produced by Saphores et al. [28] is a relevant example in the field; indeed, the author examines the propensity to buy for sustainable electronics of Californian families. In the analysis conducted by the researchers, significant predictors of the purchase of more sustainable computers and phones include age, income, education level, willingness to pay, as well as beliefs about the role of government to improve environmental quality. However, according to the results of the study, willingness to pay for sustainable electrical and electronic products is relatively low, resulting in consumers being willing to pay only $1 \%$ more than for a traditional product. Only young adults, i.e., under 36 , are willing to pay $5 \%$ to $10 \%$ more for sustainable smartphones. According to these results, therefore, it would seem that consumers expect manufacturers to innovate to make their products more environmentally friendly without significantly increasing prices. The low willingness to pay for sustainable electronics may also be caused by a further variable not investigated in this study but considered in others. Environmental knowledge in this context can be translated, for example, as poor knowledge of the toxicity of electronic waste.

Hassan and Nor [8] introduced aspects related to knowledge of environmental problems and the impact of products on the environment in the analysis of determinants of sustainable purchasing behavior towards electrical and electronic products. Knowledge of a problem significantly affects the decision-making process even in the purchasing phase. In this case, knowledge of the lower impacts of sustainable products both on the environment and therefore also on human health are in fact significant losers of purchasing behavior. Therefore, to guide lasting and significant changes in behavior, environmental values must also be developed through education by making the consumer understand how to develop approaches for sustainable products, how to interpret information, and on which additional criteria to base their decisions. However, knowledge does not always translate into sustainable environmental behavior, an aspect that is true for many types of consumption and for electronics [7]. In fact, it is important to mention the so-called "attitude-behavior gap" underlined in various research [61] according to which, although consumers report that they are aware of and are very worried about environmental issues, they then struggle to translate this concern into sustainable purchases.

Finally, also the study conducted by [7] provides an interesting overview of behaviors related to the purchase of electrical and electronic products. The authors analyze the purchasing process in relation to sustainable technology products in the UK, adding another variable of interest. In this case, in fact, the situational variables are also analyzed as predictors of sustainable consumption. The results 
show that every purchase, especially of large electronic equipment such as ovens, refrigerators, etc., is strongly linked to situational factors such as moving and is therefore is also connected to the presence of resellers of sustainable products in a neighboring area.

As presented above, while there is some research dealing with the selection of sustainable electronics products (e.g., made from recyclable materials, more durable/easily repairable products, energy efficient products, etc.), research dealing with behavior related to avoidance of purchasing unnecessary electronics products or substituting prematurely their electronics seems completely missing at present time. Still, our analysis underlines the paucity of research dealing with purchase of used and refurbished electronic products.

\subsection{Determinants and Models for Life Extension Behaviors of Electrical and Electronic Products}

At the basis of the behavior related to extension of the useful life of a product is those that, in the literature, are more generically defined as waste prevention behaviors. As reported by the European Commission [62] in the guidance document for the preparation of waste prevention programs, prevention also includes "actions that can be taken once a product reaches the end of its life cycle: rather than discarding the product, the end user prevents the formation of waste by considering options such as reuse and repair" (p.7). Tonglet et al. [63], with one of the first research on the subject, identified two variants of waste prevention behavior:

1. prevention at the time of purchase, which includes behaviors in choosing products that produce less waste (for example, products with excessive packaging or disposable products) and

2. prevention during the useful life of the product through repair or reuse behavior rather than replacement of the same.

While the first variant is very unlikely for electrical and electronic products, the second is considered relevant. For this reason, only the results and considerations arising from the latter type of behavior are reported below. To understand what are the determinants of repair or reuse behavior, Tonglet et al. [63] also used a TPB framework, investigating not only the generally expected variables (attitudes, norms, and perception of behavioral control) but also others such as the economic convenience of behavior, situational factors, concern for the community, etc. The results that emerged in the study by Tonglet et al. [63] are summarized in Figure 3.

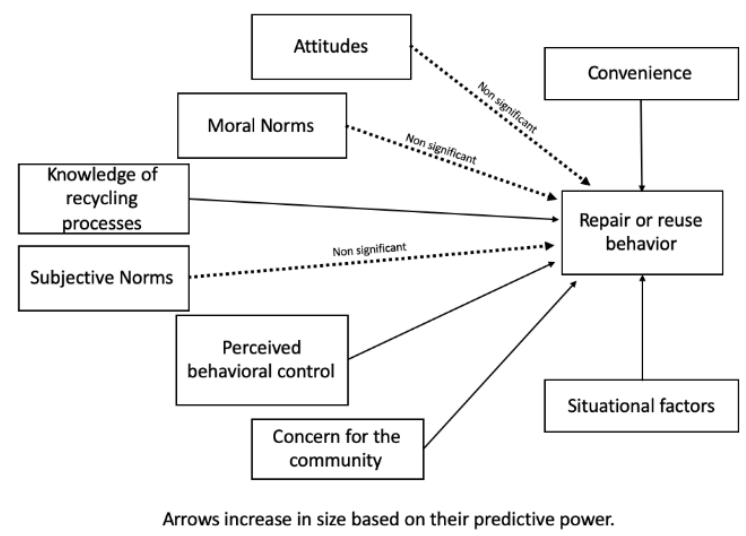

Figure 3. Model tested and results in Tonglet et al. [64].

As can be seen from Figure 4, the study shows how repair and reuse behaviors are more likely to be undertaken by subjects more inclined to worry about environmental issues and the impact of waste on the environment and the community. It should also be mentioned that factors such as individual economic convenience are relevant. 


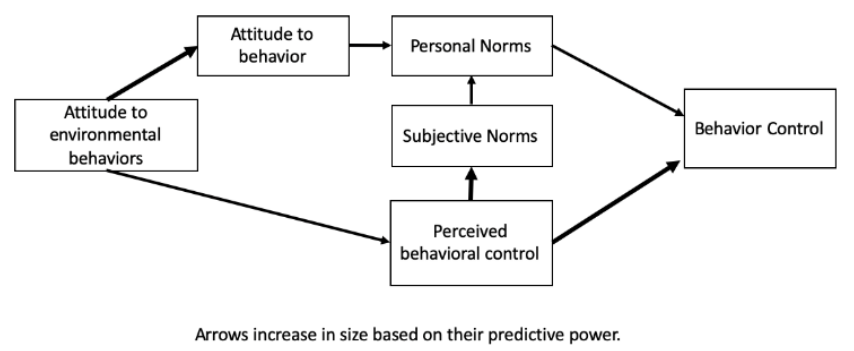

Figure 4. Model tested and results in the work of Bortoleto et al. [64].

Bortoleto et al. [64] built a model to explain general waste prevention behavior based on both the TPB and models that other researchers tested on recycling behaviors. As shown in Figure 4, the model shows how perception of behavior control and personal norms are the most significant determinants for explaining waste prevention behavior. Unlike the general model of the TPB, the insignificant influence of subjective norms can be explained as the non-visibility of waste prevention behaviors that are usually conducted inside homes (e.g., repair actions) and therefore not subject to judgment of others.

Also, in this case, as presented in Table 2, there are more specific studies in relation to extending the useful life of the electrical and electronic product through repair or reuse. For example, Pérez-Belis et al. [29] presented a survey to identify current habits and practices regarding the repair of small electrical and electronic equipment among Spanish consumers with the aim of singling out the profile of those more or less prone to this behavior. Specifically, the behaviors analyzed relate to the replacement of product parts, the repair of the same, and the purchase of small electrical and electronic products used. The results of the study show that Spanish consumers use small household electrical and electronic appliances for an average of 6.25 years. Only $9 \%$ of respondents have never repaired these products, while less than $1 \%$ buy second-hand products. The analysis of the relationship between consumer attitudes and the main socioeconomic variables shows that gender and age are fundamental determinants of these behaviors. Specifically, older female consumers are more likely to carry out repairs to small household electrical and electronic equipment to extend their life, while older male consumers with average household incomes are more likely to purchase second-hand products.

The study by Bovea et al. [35] adds another level of analysis. The authors indeed examine the behavior related to repair of small household equipment (i.e., vacuum cleaner, juicers, irons, toasters, coffee makers, blenders, etc.) in relation to the variable of perception of the cost of repair. The results of the study, conducted in Spain, show how the variable perception of cost is inversely correlated with the repair behavior. Moreover, the study reported that almost $80 \%$ of the reference sample believes that the repair is not worth it given the often almost equivalent price of a new equipment. The authors investigated as well another variable in relation to the repair behavior: the perception of the safety of the repaired equipment. Also in this case, such a variable was inversely correlated to repair behavior.

Finally, another study worth mentioning was conducted by Lilley et al. [32]. The authors focused explicitly on self-repair behavior of small household equipment grounding on a survey administered to UK citizens. The research explored additional variable of interest such as personal satisfaction in self-repairing and easily accessible written information as a determinant of the behavior. According to the results of this study, self-repair behaviors would in fact be positively influenced by the sense of reward and personal satisfaction that a user can find in the technical challenge related to self-repair. Also, the availability of written information was found for a variable positively influencing self-repair behavior. Finally, the authors, unlike the previous study, reported that the economic variable linked to the purchase of the new product is significant in predicting the self-repair behavior, making the users lean towards the latter activity.

Some general considerations can be done with regards to the research produced in relation to life extension behaviors directly dealing with electrical and electronic products. Indeed, while there is some research dealing with repairing/or self-repairing electronics products, our analysis underlines the paucity of research dealing with sale and donation of electrical and electronic still functioning. 


\subsection{Determinants for Recycling Electrical and Electronic Waste}

Also, in this case, firstly, we present some general studies exploring the recycling behavior and then we move to present some more specific research explicitly dealing with the recycling of WEEE. The work of Oskamp et al. [23] represents one of the first studies on the topic of waste recycling behavior in its general meaning. To investigate the factors that encourage recycling behavior, the authors examined different types of variables such as

- demographic variables: age, education, income, children, type of home, and ownership of the home;

- variables of knowledge of the state of environmental conservation;

- ecological attitudinal variables, awareness of environmental problems, personal motivation, participation in community life, the feeling of effectiveness of one's environmental behavior, and awareness of the importance of recycling; and

- behavioral variables such as past behavior related to recycling and recycling behavior of friends and neighbors.

The study results underline that most demographic variables do not predict recycling behavior; only ownership of the house and level of education showed positive correlations with recycling behavior. Indeed, those owning their own house and those with a higher education level were found more willing to participate in recycling activities.

The study also highlights how ecological attitudes, personal motivations, awareness of environmental problems, and the recycling behavior of friends and neighbors are the main drivers.

Another major study which seeks to understand the drivers that lead an individual to recycle waste is that of Barr et al. [65]. The analysis used a conceptual framework of environmental behavior previously developed by Barr et al. [66] on the relationship between environmental values, situational factors, and psychological variables and the declared intention to act with respect to waste management. The conceptual framework described is shown in Figure 5.

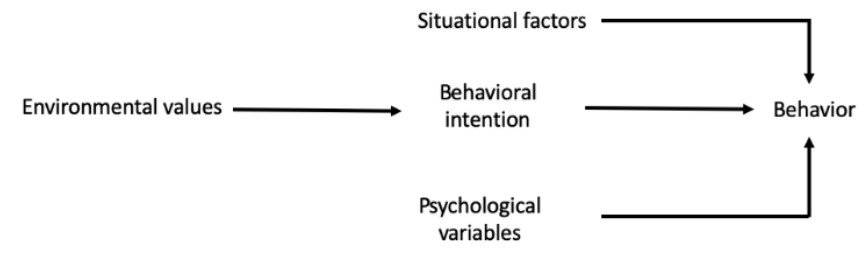

Figure 5. Conceptual frame of reference in Barr's [65] work.

Unlike the studies cited above, it can be noted that, in this case, not only the intentions and variables of a psychological nature but also some situational factors that refer to the availability of door-to-door separate collection systems are taken into consideration. The results of the analysis by Barr et al. [65] are shown in Figure 6, which depicts that the recycling behavior is determined not only by the willingness to recycle but also by the knowledge of what can be recycled and by the commitment and infrastructural presence of a door-to-door collection method. The knowledge of what can be recycled and the presence of a door-to-door collection system represent procedural knowledge and a situational factor, respectively, both of which are fundamental for determining recycling behavior.

Also, in this case, there are also specific examples of models that analyze waste recycling behaviors from electrical and electronic equipment.

Darby and Obara [36] analyzed the domestic recycling behavior towards small electrical and electronic equipment. In this case, the variables that are taken into consideration are different and refer to both demographic and psychological variables. Specifically, the research shows that there is a substantial lack of awareness about the correct management of this waste, demonstrated by the fact that most of the samples do not consider knowing how such waste is sent for recovery or disposal to be important. This lack of awareness inhibits recycling behavior. Research shows that this lack of awareness is less relevant when it comes to large electrical and electronic equipment. Greater sensitivity 
is demonstrated by the fact that the investigated sample was able to provide adequate details to correctly identify the methods of disposal of such waste based on specific past events (e.g., house removals, house renovations, etc.). In addition to the aspect linked to awareness, the researchers underline that there is a substantial difference in behavior regarding the annual income of families. Families with lower income would be less prone to recycling of small WEEEs. The authors justify this information with the difficulty of accessing means of transport, such as owned cars, as the collection centers where these WEEEs are delivered are usually located in areas adjacent to inhabited centers. Finally, the last significant determinant presented in the study is the attitude to recycling in general. In fact, the attitude of recycling other types of household waste, such as packaging, impacts the way in which small WEEEs are disposed of. Interpretations of the significance of this variable are to be found in the fact that users who recycle other waste streams on a regular basis usually visit the collection centers with the intention of disposing of small WEEEs, considering that a large part of them is sent for recycling. Secondly, this variable may indicate a "spill-over" effect, whereby the recycling behavior of other waste streams has led to a change in overall behavior also on the management of small-sized WEEEs.

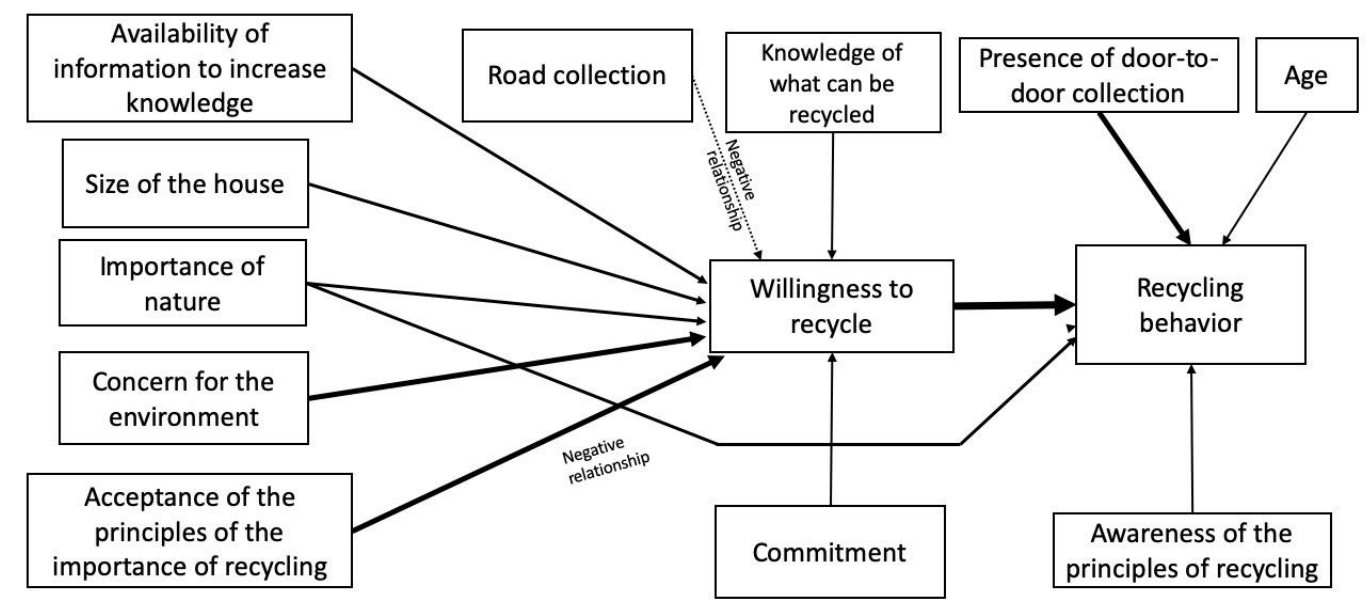

Arrows increase in size based on their predictive power.

Figure 6. Variables that influence recycling behavior according to Barr [65].

Difficulty in accessing collection centers is also a significant variable in the study by Ylä-Mella et al. [9] who analyzed consumer awareness and behavior towards cell phone recycling in Finland. The authors, on the basis of the survey carried out, underlined that the current methods and regional WEEE collection infrastructures are relatively known to residents and that they also have a good awareness of the environmental benefits associated with WEEE recycling activities. However, only half of the respondents in the sample indicated that they chose to recycle such waste, preferring to store it in homes, as the proximity and convenience of the current system are not sufficient to justify the recycle startup behavior. In this context, it is therefore the situational variables linked to the collection system that prevent awareness from translating into actual behavior.

As access to collection centers represents a significant aspect in determining WEEE collection all over the world, in some countries, new approaches to recycling are emerging. Online recycling is a new modality of recycling WEEE that is emerging in China [67]. Online recycling is a new method for collecting WEEE to be recycled whereby residents use an Internet-based platform to book the collection of their waste. Some recent research exploring WEEE recycling behaviors focus explicitly on online recycling. For instance, Wang et al. [44] adopted a theoretical framework grounding on the TPB to explore Chinese residents' willingness to be involved in WEEE online recycling. Their results (Figure 7) show that perceived behavioral control, subjective norms, attitudes, economic motivation, education, and income have significantly positive impacts on the willingness to online recycle. Moreover, the author tested whether the income of residents moderates the role of economic motivation in residents' 
willingness to take part in WEEE online recycling and if the level of education moderates the effect of subjective norms on the behavior. Their results show that residents with higher incomes are less interested in the economic benefits of participating in online recycling and that education level does not have a moderating effect on willingness to participate in WEEE online recycling.

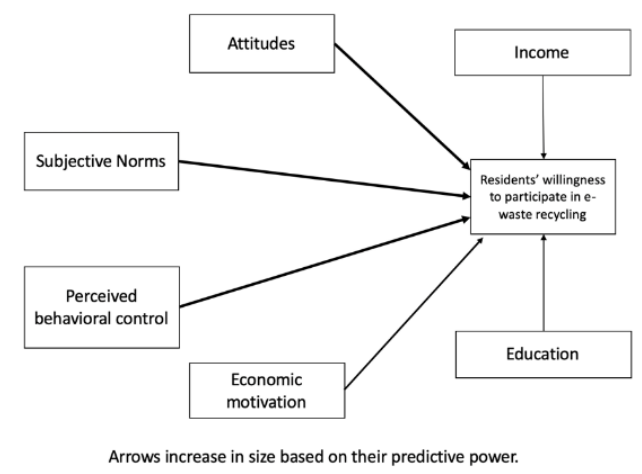

Figure 7. Variables that influence online recycling behavior according to Wang et al. [44].

\subsection{Determinants for Participation Behavior in Tack-Back Initiatives}

Finally, it is also necessary to mention the behavior of participating in take-back schemes that several companies are setting up during the last years. More in detail, take-back are initiatives organized by a producer to collect used products or products reaching their end of life from consumers and to reintroduce them to the original processing and manufacturing cycle. Generally, a company may implement this initiative in collaboration with end-of-life logistics or with a material processing company [68].

Scientific contributions emerging on this type of end-of-life WEEE management behavior are relatively less in comparison to the WEEE recycling behavior presented in Table 2. Motivation might be related to the fact that take-back initiatives are relatively new kind of initiatives [69] and to the fact that there might be substantial barriers for companies to implement such activities [70]. It is also interesting to notice that almost all the scientific contributions exploring consumer behavior in relation to the participation in take-back initiatives deal with used EEEs or WEEEs as those represent the products with the highest value to recover with a take-back process [71].

An example of the study conducted in this field is the one authored by Kianpour et al. [57]. The authors explored factors that influence consumer behavior in returning electronic products at the end of their life through voluntary take-back initiatives established by private companies in Malaysia. Also, in this case, the authors, as shown in Figure 8, used a modified version of the TPB to investigate the user's participation in voluntary take-back initiatives implemented by manufacturing companies.

The results show that consumer perception of the risk associated with end-of-life electronic products, consumer knowledge, and the related benefits associated with reuse, repair, and recycling can influence consumer behavior by incentivizing them to return end-of-life products in take-back initiatives activated directly by producers. Furthermore, the results of the study confirm that both the way in which companies collect their electronic products at the end of their life in terms of accessibility and the information made available can influence the user's perception of behavioral control and how this affects the behavior of participation in take-back initiatives.

Another research in this field has been carried out by Botelho et al. [55] with the aim to determine the determinants of consumers' behavior in relation to five incentive schemes for the take-back of waste electrical and electronic equipment in Portugal. The authors, without adopting a specific theoretical framework, analyzed the sociodemographic factors that significantly influence consumer behavior in the take-back initiatives and the additional motivations influencing such behavior. The results denote that the lack of awareness of consumers about the process of take-back established by companies is a significant variable negatively influencing participation behavior. It is interesting to notice that whether 
the take-back scheme is in place with an "exchange for money" or "coupon discount" agreement, monthly income exerts a negative influence on the likelihood of consumers" participation. On the other hand, the education level of the consumer positively influences the likelihood of participation if a "tax benefit" agreement kind of incentive is in place in the scheme. All in all, authors underline the fact that, in Portugal, the adoption of such kinds of initiatives related to WEEEs is still in its infancy, like in many other countries.

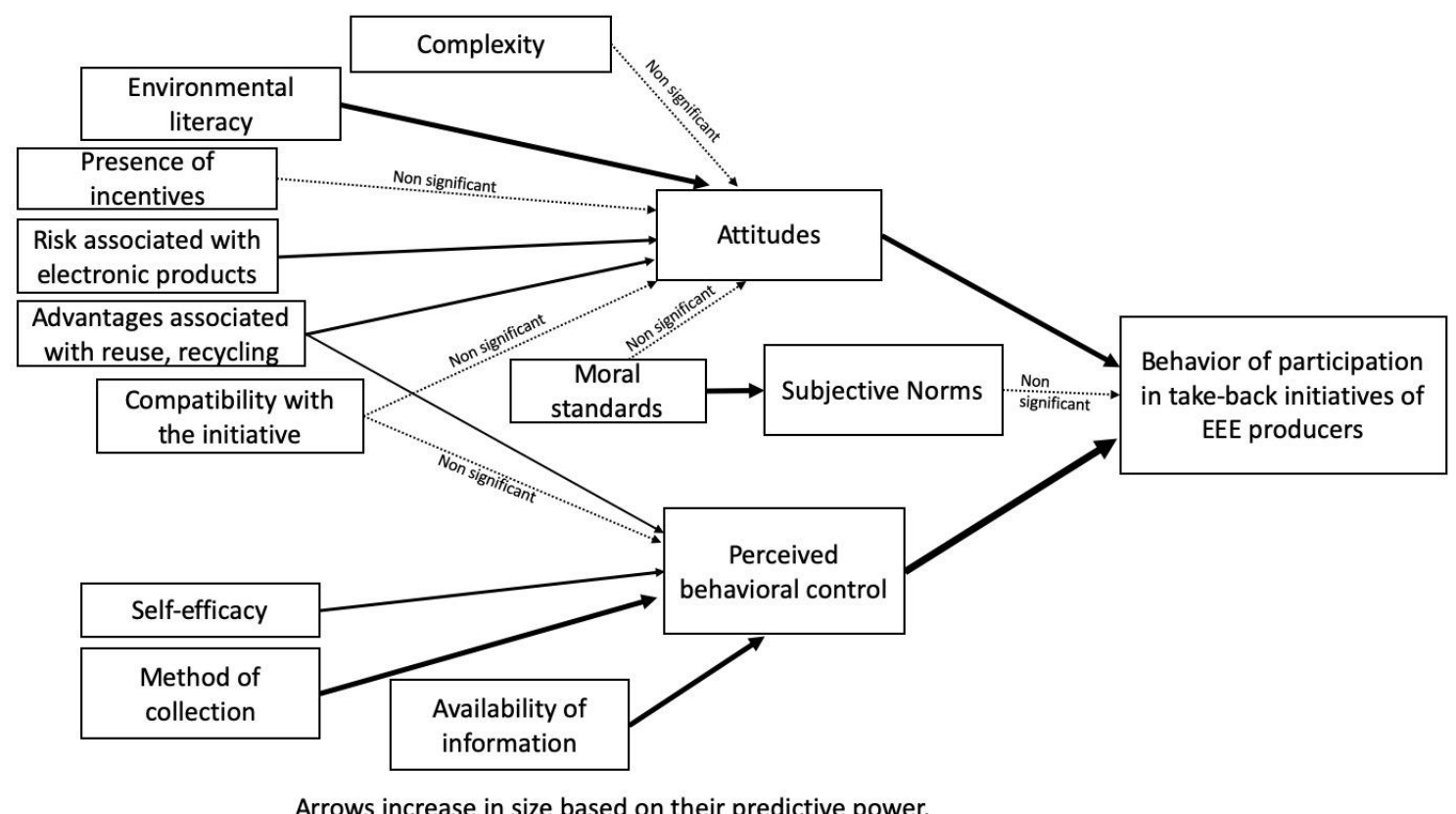

Figure 8. Variables influencing the behavior of participation in take-back initiatives according to Kianpour et al. [57].

\section{Conclusions}

This review article analyzes the four types of consumer behavior related to purchases, extension of useful life, and management of end of life of electrical and electronic equipment. In particular, some of the results of academic research published on such topics are presented and discussed, showing how psychological variables, sociodemographic variables, situational factors, and costs influence a certain behavior.

As presented in the previous paragraphs, there are plenty of research exploring the determinants of WEEE recycling behavior, referring to different recycling practices (e.g., online recycling) and in relation to different geographical areas. Other typologies of behaviors are less analyzed in the literature. In particular, the investigation conducted denotes the paucity of research analyzing purchasing behaviors related to second-hand and refurbished EEE products and those related to the resale or donation of electrical and electronic products still functioning. Future research could deepen the understanding of such behaviors as those are also relevant in achieving the full circularity of the EEE value chain.

Also, the determinants of consumer behavior linked to the extension of useful life might be fostered in future research. A deep understanding of such behavior is also relevant for companies that can acquire new business opportunities by extending the useful life of their product. In fact, the lower number of product units sold can be offset by the revenues generated through a range of complementary services (e.g., repair, sale of parts for repair, etc.). A better understanding of such behavior from consumers could help explain how companies choosing to ease reparation of their products could benefit from greater customer loyalty, which in fact shows greater confidence in companies sensitive to environmental dynamics. Moreover, by deepening the habits and behaviors of consumers on the behavior of extending the useful life of a product, companies can acquire unique knowledge about the preferences, needs, 
and desires of customers as the level of contact between the parties will increase through the services provided. This information can also help companies define more targeted future offers.

Our research underlines also that studies exploring the behavior of participating in take-back schemes are still in its infancy and almost exclusively dealing with EEE or WEEE. We expect in the near future an advent of more research on such topics as many other business sectors implement take-back initiatives such as the textile and fashion industry [72].

Some general considerations can be done also with regards to the aspects explored in the studies reviewed. Considering all the papers reviewed, also in this field, like in others, there is no consistent trend between sociodemographic variables and circular consumer's behavior in relation to the purchase, extension of life, and end of life management of electrical and electronic products. Also, in this case, indeed, the ability to explain such circular behaviors through sociodemographic variables is quite limited [20].

Moreover, what emerges from all the studies identified is that, although there are not numerous studies on the behaviors related to the purchase, extension of the useful life, and management of large electrical and electronic equipment, it is still possible to infer that there are major differences in the determinants of such behaviors with those related to small-sized equipment.

The theoretical model adopted in many studies reveals its usefulness to predict the determinist of such circular consumer's behavior in relation to the purchase, extension of life, and end of life management of electrical and electronic products; however, in many cases, additional variables are needed to fully explain the behavior.

On a theoretical level, all the studies presented address the issue of behavior from the point of view of the single individual. However, many behaviors and practices such as purchasing certain products are actions that are widely shared between individuals. Future research may use different theoretical approaches such as "social practice theory" to analyze these behaviors [73]. Such a theoretical approach, for example, considers excessive forms of consumption not as a problem of individual consumer behavior but rather as behaviors incorporated into the prevailing organization of social practices or what people consider normal and shared lifestyles and ways of life.

Author Contributions: Conceptualization, F.C., N.M.G. and M.F.; methodology F.C., N.M.G. and M.F.; investigation, F.C., N.M.G. and M.F.; writing-original draft preparation, F.C., N.M.G. and M.F.; writing-review and editing, F.C., N.M.G. and M.F. All authors have read and agreed to the published version of the manuscript.

Funding: This research received no external funding

Conflicts of Interest: The authors declare no conflict of interest

\section{References}

1. Bocken, N.; Miller, K.; Evans, S. Assessing the Environmental Impact of New Circular Business Models. In Proceedings of the "New Business Models"-Exploring a Changing View on Organizing Value Creation, Toulouse, France, 16-17 June 2016.

2. Kirchherr, J.; Reike, D.; Hekkert, M. Conceptualizing the Circular Economy: An Analysis of 114 Definitions. Resour. Conserv. Recycl. 2017, 127, 221-232. [CrossRef]

3. Balde, K.; Wang, F.; Huisman, J.; Kuehr, R. The Global E-Waste Monitor; United Nations University, IAS-SCYCLE: Bonn, Germany, 2015.

4. Cucchiella, F.; D'Adamo, I.; Lenny Koh, S.C.; Rosa, P. Recycling of WEEEs: An Economic Assessment of Present and Future e-Waste Streams. Renew. Sustain. Energy Rev. 2015, 51, 263-272. [CrossRef]

5. European Commission. Communication from the Commission to the European Parliament, the Council, the European Economic and Social Committee and the Committee of the Regions: A New Circular Economy Action Plan, COM (2020) 98 final. 2020. Available online: https:/eur-lex.europa.eu/legal-content/EN/TXT/ HTML/?uri=CELEX:52020DC0098\&from=EN (accessed on 20 November 2020).

6. Corsini, F.; Rizzi, F.; Frey, M. Extended Producer Responsibility: The Impact of Organizational Dimensions on WEEE Collection from Households. Waste Manag. 2017, 59, 23-29. [CrossRef]

7. Young, W.; Hwang, K.; McDonald, S.; Oates, C.J. Sustainable Consumption: Green Consumer Behaviour When Purchasing Products. Sustain. Dev. 2010, 18, 20-31. [CrossRef] 
8. Hassan, Y.; Nor, M.N.A.M. Understanding Consumer Decision Making Towards Green Electronic Products. In Proceedings of the Kuala Lumpur International Business, Economics and Law Conference, Kuala Lumpur, Malaysia, 8-9 April 2013; Volume 31.

9. Ylä-Mella, J.; Keiski, R.L.; Pongrácz, E. Electronic Waste Recovery in Finland: Consumers' Perceptions Towards Recycling and Re-use of Mobile Phones. Waste Manag. 2015, 45, 374-384. [CrossRef]

10. Nowakowski, P. The Influence of Residents' Behaviour on Waste Electrical and Electronic Equipment Collection Effectiveness. Waste Manag. Res. 2016, 34, 1126-1135. [CrossRef] [PubMed]

11. Ardi, R.; Iqbal, B.M.; Sesarea, S.; Komarudin, K. What Drives Individuals to Dispose of Waste Mobile Phones? A Case Study in Indonesia. Int. J. Technol. 2020, 11, 631-641. [CrossRef]

12. Thurstone, L.L. Attitudes Can Be Measured. Am. J. Sociol. 1928, 33, 529-554. [CrossRef]

13. Katz, D.; Stotland, E. A Preliminary Statement to a Theory of Attitude Structure and Change. In Psychology: A Study of a Science: Vol. 3 Formulations of the Person and the Social Context; McGraw-Hill: New York, NY, USA, 1959; pp. 423-475.

14. Smith, M.B.; Bruner, J.S.; White, R.W. Opinions and Personality; Wiley: New York, NY, USA, 1956.

15. Cialdini, R.B.; Reno, R.R.; Kallgren, C.A. A Focus Theory of Normative Conduct: Recycling the Concept of Norms to Reduce Littering in Public Places. J. Personal. Soc. Psychol. 1990, 58, 1015-1026. [CrossRef]

16. Grob, A. A Structural Model of Environmental Attitudes and Behaviour. J. Environ. Psychol. 1995, 15, $209-220$. [CrossRef]

17. Ajzen, I. The Theory of Planned Behaviour. Organ. Behav. Hum. Decis. Proces. 1991, 50, 179-211. [CrossRef]

18. Kurisu, K. Pro-Environmental Behaviors; Springer: Tokyo, Japan, 2015.

19. Raudsepp, M. Some Socio-Demographic and Socio-Psychological Predictors of Environmentalism. Trames 2001, 5, 355-367.

20. Patel, J.; Modi, A.; Paul, J. Pro-Environmental Behavior and Socio-Demographic Factors in an Emerging Market. Asian J. Bus. Ethics 2017, 6, 189-214. [CrossRef]

21. Diekmann, A.; Preisendörfer, P. Green and Greenback: The Behavioral Effects of Environmental Attitudes in Low-Cost and High-Cost Situations. Ration. Soc. 2003, 15, 441-472. [CrossRef]

22. Kaiser, F.G.; Fuhrer, U. Ecological Behavior's Dependency on Different Forms of Knowledge. Appl. Psychol. 2003, 52, 598-613. [CrossRef]

23. Oskamp, S.; Harrington, M.J.; Edwards, T.C.; Sherwood, D.L.; Oku-da, S.M.; Swanson, D.C. Factors Influencing Household Recycling Behavior. Environ. Behav. 1991, 23, 494-519. [CrossRef]

24. Rotter, J.B. Generalized Expectancies for Internal Versus External Control of Reinforcement. Psychol. Monogr. Gen. Appl. 1966, 80, 1-28. [CrossRef]

25. Steg, L.; Bolderdijk, J.W.; Keizer, K.; Perlaviciute, G. An Integrated Framework for Encouraging Pro-Environmental Behaviour: The Role of Values, Situational Factors and Goals. J. Environ. Psychol. 2014, 38, 104-115. [CrossRef]

26. Schultz, P.W.; Oskamp, S.; Mainieri, T. Who Recycles and When? A Review of Personal and Situational Factors. J. Environ. Psychol. 1995, 15, 105-121. [CrossRef]

27. Light, R.J.; Pillemer, D.B. Summing Up; The Science of Reviewing Research; Harvard University Press: Cambridge, MA, USA, 1984.

28. Saphores, J.D.M.; Nixon, H.; Ogunseitan, O.A.; Shapiro, A.A. California Households' Willingness to Pay for 'Green' Electronics. J. Environ. Plan. Manag. 2007, 50, 113-133. [CrossRef]

29. Pérez-Belis, V.; Braulio-Gonzalo, M.; Juan, P.; Bovea, M.D. Consumer Attitude Towards the Repair and the Second-Hand Purchase of Small Household Electrical and Electronic Equipment. A Spanish Case Study. J. Clean. Prod. 2017, 158, 261-275. [CrossRef]

30. Danish, M.; Ali, S.; Ahmad, M.A.; Zahid, H. The Influencing Factors on Choice Behavior Regarding Green Electronic Products: Based on the Green Perceived Value Model. Economies 2019, 7, 99. [CrossRef]

31. Gutiérrez, E.; Adenso-Díaz, B.; Lozano, S.; González-Torre, P. Lifetime of Household Appliances: Empirical Evidence of Users Behaviour. Waste Manag. Res. 2011, 29, 622-633. [CrossRef] [PubMed]

32. Lilley, D.; Bailey, V.; Charnley, F. Design for Sustainable Behaviour: A Quick Fix for Slower Consumption? In Proceedings of the 16th Conference of the European Roundtable on Sustainable Consumption and Production (ERSCP) \& 7th Conference of the Environmental Management for Sustainable Universities (EMSU) (ERSCP -EMSU 2013), Istanbul, Turkey, 4-7 June 2013; p. 26. Available online: https://www.researchgate.net/ publication/303749333_DESIGN_FOR_SUSTAINABLE_BEHAVIOUR_A_QUICK_FIX_FOR_SLOWER_ CONSUMPTION (accessed on 10 December 2020). 
33. Hennies, L.; Stamminger, R. An Empirical Survey on the Obsolescence of Appliances in German Households. Resour. Conserv. Recycl. 2016, 112, 73-82. [CrossRef]

34. Pérez-Belis, V.; Bakker, C.; Juan, P.; Bovea, M.D. Environmental Performance of Alternative End-of-Life Scenarios for Electrical and Electronic Equipment: A Case Study for Vacuum Cleaners. J. Clean. Prod. 2017, 159, 158-170. [CrossRef]

35. Bovea, M.D.; Pérez-Belis, V.; Quemades-Beltrán, P. Attitude of the Stakeholders Involved in the Repair and Second-Hand Sale of Small Household Electrical and Electronic Equipment: Case Study in Spain. J. Environ. Manag. 2017, 196, 91-99. [CrossRef]

36. Darby, L.; Obara, L. Household Recycling Behaviour and Attitudes Towards the Disposal of Small Electrical and Electronic Equipment. Resour. Conserv. Recycl. 2005, 44, 17-35. [CrossRef]

37. Wang, Z.; Zhang, B.; Yin, J.; Zhang, X. Willingness and Behavior Towards e-Waste Recycling for Residents in Beijing City, China. J. Clean. Prod. 2011, 19, 977-984. [CrossRef]

38. Li, J.; Liu, L.; Ren, J.; Duan, H.; Zheng, L. Behavior of Urban Residents Toward the Discarding of Waste Electrical and Electronic Equipment: A Case Study in Baoding, China. Waste Manag. Res. 2012, 30, 1187-1197. [CrossRef]

39. Chi, X.; Wang, M.Y.; Reuter, M.A. E-Waste Collection Channels and Household Recycling Behaviors in Taizhou of China. J. Clean. Prod. 2014, 80, 87-95. [CrossRef]

40. Belis, V.P.; Bovea, M.; Simó, A. Consumer Behaviour and Environmental Education in the Field of Waste Electrical and Electronic Toys: A Spanish Case Study. Waste Manag. 2015, 36, 277-288. [CrossRef] [PubMed]

41. Bovea, M.; Forés, V.I.; Bayarri-Porcar, V.; Juan, P. A Survey on Consumers' Attitude Towards Storing and End of Life Strategies of Small Information and Communication Technology Devices in Spain. Waste Manag. 2018, 71, 589-602. [CrossRef] [PubMed]

42. Nowakowski, P. Investigating the Reasons for Storage of WEEE by Residents-A Potential for Removal from Households. Waste Manag. 2019, 87, 192-203. [CrossRef] [PubMed]

43. Shevchenko, T.; Laitala, K.; Danko, Y. Understanding Consumer E-Waste Recycling Behavior: Introducing a New Economic Incentive to Increase the Collection Rates. Sustainability 2019, 11, 2656. [CrossRef]

44. Wang, B.; Ren, C.; Dong, X.; Zhang, B.; Wang, Z. Determinants Shaping Willingness Towards On-line Recycling Behaviour: An Empirical Study of Household e-Waste Recycling in China. Resour. Conserv. Recycl. 2019, 143, 218-225. [CrossRef]

45. Kumar, A. Exploring Young Adults' e-Waste Recycling Behaviour Using an Extended Theory of Planned Behaviour Model: A Cross-Cultural Study. Resour. Conserv. Recycl. 2019, 141, 378-389. [CrossRef]

46. Borthakur, A.; Govind, M. Computer and Mobile Phone Waste in Urban India: An Analysis from the Perspectives of Public Perception, Consumption and Disposal Behaviour. J. Environ. Plan. Manag. 2019, 62,717-740. [CrossRef]

47. Park, J.; Kim, S.D.; Choi, S.O. Demonstrating the Effects of Behavioral Control Beliefs on the Actual WEEE Discharge Routes: A Case Study in South Korea. Resour. Conserv. Recycl. 2020, 163, 105088. [CrossRef]

48. Kurisu, K.; Miura, J.; Nakatani, J.; Moriguchi, Y. Hibernating Behavior for Household Personal Computers. Resour. Conserv. Recycl. 2020, 162, 105015. [CrossRef]

49. Mansuy, J.; Verlinde, S.; Macharis, C. Understanding Preferences for EEE Collection Services: A Choice-Based Conjoint Analysis. Resour. Conserv. Recycl. 2020, 161, 104899. [CrossRef]

50. Hamdan, S.; Saidan, M.N. Estimation of E-waste Generation, Residential Behavior, and Disposal Practices from Major Governorates in Jordan. Environ. Manag. 2020, 66, 884-898. [CrossRef] [PubMed]

51. Huang, H.; Tong, X.; Cai, Y.; Tian, H. Gap between Discarding and Recycling: Estimate Lifespan of Electronic Products by Survey in Formal Recycling Plants in China. Resour. Conserv. Recycl. 2020, 156, 104700. [CrossRef]

52. Delcea, C.; Craciun, L.; Ioanăș, C.; Ferruzzi, G.; Cotfas, L.A. Determinants of Individuals' E-Waste Recycling Decision: A Case Study from Romania. Sustainability 2020, 12, 2753. [CrossRef]

53. Manomaivibool, P.; Vassanadumrongdee, S. Buying Back Household Waste Electrical and Electronic Equipment: Assessing Thailand's Proposed Policy in Light of Past Disposal Behavior and Future Preferences. Resour. Conserv. Recycl. 2012, 68, 117-125. [CrossRef]

54. Sabbaghi, M.; Behdad, S.; Zhuang, J. Managing Consumer Behavior Toward On-Time Return of the Waste Electrical and Electronic Equipment: A Game Theoretic Approach. Int. J. Prod. Econ. 2016, 182, 545-563. [CrossRef]

55. Botelho, A.; Dias, M.F.; Ferreira, C.C.; Pinto, L.M.C. The Market of Electrical and Electronic Equipment Waste in Portugal: Analysis of Take-Back Consumers' Decisions. Waste Manag. Res. 2016, 34, 1074-1080. [CrossRef] 
56. Budijati, S.M.; Subagyo; Wibisono, M.A.; Masruroh, N.A. Influence of Government and Economic Drivers on Consumers' Intentions to Participate in a Take Back Program. Int. J. Logist. Syst. Manag. 2016, 23, 343-362. [CrossRef]

57. Kianpour, K.; Jusoh, A.; Mardani, A.; Streimikiene, D.; Cavallaro, F.; Nor, K.M.; Zavadskas, E. Factors Influencing Consumers' Intention to Return the End of Life Electronic Products Through Reverse Supply Chain Management for Reuse, Repair and Recycling. Sustainability 2017, 9, 1657. [CrossRef]

58. Kumar, A. Extended TPB Model to Understand Consumer “Selling” Behaviour. Asia Pac. J. Mark. Logist. 2017, 29, 721-742. [CrossRef]

59. Joshi, Y.; Rahman, Z. Factors Affecting Green Purchase Behaviour and Future Research Directions. Int. Strat. Manag. Rev. 2015, 3, 128-143. [CrossRef]

60. Moser, A.K. Thinking Green, Buying Green? Drivers of Pro-Environmental Purchasing Behavior. J. Consum. Mark. 2015, 32, 167-175. [CrossRef]

61. Defra. Sustainable Consumption and Production: Encouraging Sustainable Consumption. 2006. Available online: http://www.sustainable-development.gov.uk/what/priority/consumption-production/consumption. html (accessed on 18 November 2020).

62. European Commission. Preparing a Waste Prevention Programme. Guidance Document; European Commission: Brussels, Belgium, 2012.

63. Tonglet, M.; Phillips, P.S.; Read, A.D. Using the Theory of Planned Behaviour to Investigate the Determinants of Recycling Behaviour: A Case Study from Brixworth, UK. Resour. Conserv. Recycl. 2004, 41, 191-214. [CrossRef]

64. Bortoleto, A.P.; Kurisu, K.H.; Hanaki, K. Model Development for Household Waste Prevention Behaviour. Waste Manag. 2012, 32, 2195-2207. [CrossRef] [PubMed]

65. Barr, S.; Ford, N.J.; Gilg, A.W.; Barr, S.; Ford, N.J.; Gilg, A.W. Attitudes Towards Recycling Household Waste in Exeter, Devon: Quantitative and Qualitative Approaches. Local Environ. 2003, 8, 407-421. [CrossRef]

66. Barr, S.; Gilg, A.W.; Ford, N.J. A Conceptual Framework for Understanding and Analysing Attitudes Towards Household Waste Management. Environ. Plan. A 2001, 33, 2025-2048. [CrossRef]

67. Wang, C.; Zhu, T.; Yao, H.; Sun, Q. The Impact of Green Information on the Participation Intention of Consumers in Online Recycling: An Experimental Study. Sustainability 2020, 12, 2498. [CrossRef]

68. Corsini, F.; Rizzi, F.; Frey, M. Institutional Legitimacy of Non-Profit Innovation Facilitators: Strategic Postures in Regulated Environments. Technol. Soc. 2018, 53, 69-78. [CrossRef]

69. Esenduran, G.; Kemahlığlu-Ziya, E. A Comparison of Product Take-Back Compliance Schemes. Prod. Oper. Manag. 2015, 24, 71-88. [CrossRef]

70. Whalen, K.A.; Milios, L.; Nussholz, J. Bridging the Gap: Barriers and Potential for Scaling Reuse Practices in the Swedish ICT Sector. Resour. Conserv. Recycl. 2018, 135, 123-131. [CrossRef]

71. Ilankoon, I.; Ghorbani, Y.; Chong, M.N.; Herath, G.; Moyo, T.; Petersen, J. E-Waste in the International Context-A Review of Trade Flows, Regulations, Hazards, Waste Management Strategies and Technologies for Value Recovery. Waste Manag. 2018, 82, 258-275. [CrossRef]

72. Hvass, K.K.; Pedersen, E.R.G. Toward Circular Economy of Fashion. J. Fash. Mark. Manag. Int. J. 2019, 23, 345-365.

73. Corsini, F.; Laurenti, R.; Meinherz, F.; Appio, F.P.; Mora, L. The Advent of Practice Theories in Research on Sustainable Consumption: Past, Current and Future Directions of the Field. Sustainability 2019, 11, 341. [CrossRef]

Publisher's Note: MDPI stays neutral with regard to jurisdictional claims in published maps and institutional affiliations.

(C) 2020 by the authors. Licensee MDPI, Basel, Switzerland. This article is an open access article distributed under the terms and conditions of the Creative Commons Attribution (CC BY) license (http://creativecommons.org/licenses/by/4.0/). 